\title{
¿Hacia un proceso de litoralización? Análisis geohistórico de los partidos de La Costa, Pinamar y Villa Gesell (Buenos Aires)
}

\author{
Towards a process of littoralization? Geohistorical analysis of the \\ municipalities of La Costa, Pinamar and Villa Gesell (Buenos Aires)
}

\author{
Mario Alejandro Maya \\ mayamarioalejandro@gmail.com \\ Centro de Investigaciones Geográficas y Socio- \\ Ambientales (CIGSA). Instituto de Humanidades \\ y Ciencias Sociales (INHUS). Facultad de \\ Humanidades. Universidad Nacional de Mar del Plata. \\ CONICET, Argentina
}

Recepción: 21 Marzo 2021

Aprobación: 24 Agosto 2021

Publicación: 01 Noviembre 2021

Cita sugerida Maya, M.A. (2021). ¿Hacia un proceso de litoralización? Análisis geohistórico de los partidos de La Costa, Pinamar y Villa Gesell (Buenos Aires). Geograficando, 17(2), e100.

https://doi.org/10.24215/2346898Xe100

\begin{abstract}
Resumen: Los espacios litorales constituyen áreas de extraordinaria importancia para los seres humanos. Son espacios de una gran significación desde el punto de vista natural, social, político y económico. El presente trabajo realiza una aproximación a las características de ocupación del territorio costero en los Partidos de La Costa, Pinamar y Villa Gesell. Para ello, se utilizó la técnica de análisis geohistórico con el objetivo de analizar la evolución espacio/temporal del área objeto de estudio hacia el proceso de litoralización. La periodización elaborada permite reconocer las modificaciones vinculadas con la presión antrópica ejercida sobre el espacio litoral. La finalidad es comunicar la situación actual de los municipios para orientar acciones conducentes a un manejo integral de las áreas costeras como herramienta de gestión. Los resultados reflejan que el espacio analizado ha modificado, de manera determinante, su impronta fundacional y se hallan inmersos, en mayor o menor medida, en un proceso de litoralización. Originalmente fueron concebidas como un entorno escénico para una vida social alejada de la actividad cotidiana y adecuadas para realizar actividades recreativas y el disfrute de los paisajes. En cambio, la conjunción de actividades económicas, el aumento de la población y la expansión de emprendimientos urbanos cerrados han evolucionado sin una planificación sostenible. Si las autoridades municipales no toman medidas que propongan un manejo integrado de dicho espacio para una gestión planificada, la misma devendrá en una progresiva degradación del espacio litoral estudiado.
\end{abstract}

Palabras clave: Litoralización, Análisis geohistórico, Espacio litoral, Urbanización cerrada.

Abstract: Littoral or coastal spaces are areas of extraordinary importance for human beings. They are spaces of great significance from the natural, social, political and economic point of view. The present work offers an approximation to the occupation characteristics of the littoral territory in the Municipalities (Partidos) of La Costa, Pinamar and Villa Gesell. To this end, the geohistorical analysis technique was used in order to analyze the spatial/temporal evolution of the area under study towards the littoralization process. The resulting 
periodization allows us to recognize the modifications related to the anthropic pressure exerted on the littoral space. The purpose is to visibilize the current situation in the municipalities to guide actions leading to an integral management of the coastal areas as a management tool. The results reflect that the analyzed space has decisively modified its founding imprint and is immersed, to a greater or lesser extent, in a littoralization process. They were originally conceived of as scenic environments for a social life away from everyday life and suitable for recreational activities and the enjoyment of landscapes. Instead, the conjunction of economic activities, the increase in population and the expansion of gated urban development have evolved without sustainable planning. If the municipal authorities do not take measures to propose an integrated administration of said space for planned management, a progressive degradation of the littoral space studied will result.

Keywords: Littoralization, Geohistorical Analysis, Littoral Space, Gated Communities.

\section{INTRODUCCIÓN}

Los espacios litorales constituyen área de extraordinaria importancia para los seres humanos. Más de un tercio de la población mundial se emplaza en áreas costeras. Son espacios de una gran significación desde el punto de vista natural, social, político y económico. A pesar de ello, estos ecosistemas extremadamente frágiles y complejos han sido expuestos a diversas intervenciones antrópicas. Según Villar, su relevancia es extrema desde varios puntos de vista como el ecológico, el social y, principalmente, el económico.

Desde la óptica ecológica, el litoral es fuente de biodiversidad, lugar de hábitat y reproducción de especies. Desde el punto de vista social, ha servido históricamente como espacio de asentamiento y producción de las sociedades. Desde lo económico, ha permitido y fundamentado el establecimiento de numerosas actividades que, en mayor o menor medida, han sido funcionalmente dependientes del mar (Villar, 2003, p. 9).

La singularidad del espacio costero constituye un factor de atracción a múltiples intervenciones de diferente naturaleza y a procesos socioeconómicos a escala mundial. En varias ciudades se ha ido obstaculizando el acceso a la orilla. Se interfiere en la calidad visual del paisaje costero causados por la acción humana o potenciados por los usos y actividades que realiza. Este trabajo enfatiza en el proceso de litoralización que se desarrolla sobre las áreas costeras. El mismo ha incrementado su impacto por el uso irracional y excesivo de la sociedad, generando un progresivo deterioro de estos sitios. A los fines del presente trabajo, se delimita el área de estudio a los Partidos de La Costa, Pinamar y Villa Gesell (Buenos Aires) con el objetivo de analizar la evolución de dicho proceso. En este caso, el desarrollo urbano, el crecimiento demográfico y, particularmente, el valor escénico que se le atribuye para uso recreativo y el desarrollo turístico, son variables de un mismo proceso.

El artículo se encuentra organizado en cinco apartados. El primero de ellos tiene como finalidad la descripción del área objeto de estudio. El propósito es destacar las particularidades que caracterizan al espacio litoral de los municipios anteriormente mencionados. Se pretende establecer la delimitación geográfica con la utilización de herramientas cartográficas. Asimismo, se detallan las características generales que determinaron su selección y que, paralelamente, permitan ser abordados en conjunto. En la segunda parte, se expone la metodología adoptada, los principales objetivos y la hipótesis que orientan el trabajo. Con la 
utilización de la técnica de análisis geohistórico, se indaga la evolución del área objeto de estudio: se pone énfasis en los cambios y continuidades vinculadas a la presión antrópica ejercida sobre el espacio litoral.

El tercer apartado consiste en el desarrollo teórico de los conceptos y los procesos centrales que orientan la investigación. Para ello, se recurre a los aportes realizados por especialistas en la materia. Asimismo, se realiza una descripción de la técnica utilizada con la intención de fundamentar su aplicación empírica al área objeto de estudio. En la cuarta parte, se presenta el análisis geohistórico efectuado con el objetivo de describir la evolución histórica del territorio y definir si el mismo se encuentra frente a un proceso de litoralización. Cabe subrayar que la investigación utiliza el análisis geohistórico para llevar a cabo una periodización en etapas. Por último, se destacan las principales conclusiones a las que se arribó en la investigación.

\section{Descripción de la zona de eStUdio}

La región costera pampeana se extiende $58.609 \mathrm{~km}^{2}$ (11,4\% del área costera total del país) e incluye 16 partidos. Las actividades predominantes de este sector costero son el turismo y la industria pesquera. En este caso, "las playas atraen la corriente turística más importante del país y existe una variada oferta de balnearios con características distintivas que incluye ciudades balnearias de gran tamaño" (Dadon y Matteucci, 2006, p. 25).

Para los efectos del presente trabajo se seleccionó, como área objeto de estudio, a los partidos de La Costa, Pinamar y Villa Gesell. En su conjunto, el territorio ocupa una superficie de $574 \mathrm{~km}^{2}$ y posee una población de 127.673 habitantes (INDEC, 2010), con una proyección de 157.373 habitantes estipulado para 2025 (INDEC, 2016). La elección de unidades políticas como recorte territorial para el estudio se ha fundamentado en criterios físico-naturales, socioeconómicos, históricos y administrativos, a saber:

a) Su localización geográfica; los Partidos se encuentran ubicados en el este de la provincia de Buenos Aires y tiene un litoral marítimo que se extiende por $160 \mathrm{~km}$, a lo largo de la costa del mar Argentino (Figura N. ${ }^{\circ}$ 1);

FIGURA N. ${ }^{\circ} 1$

Partidos de La Costa, Pinamar y Villa Gesell

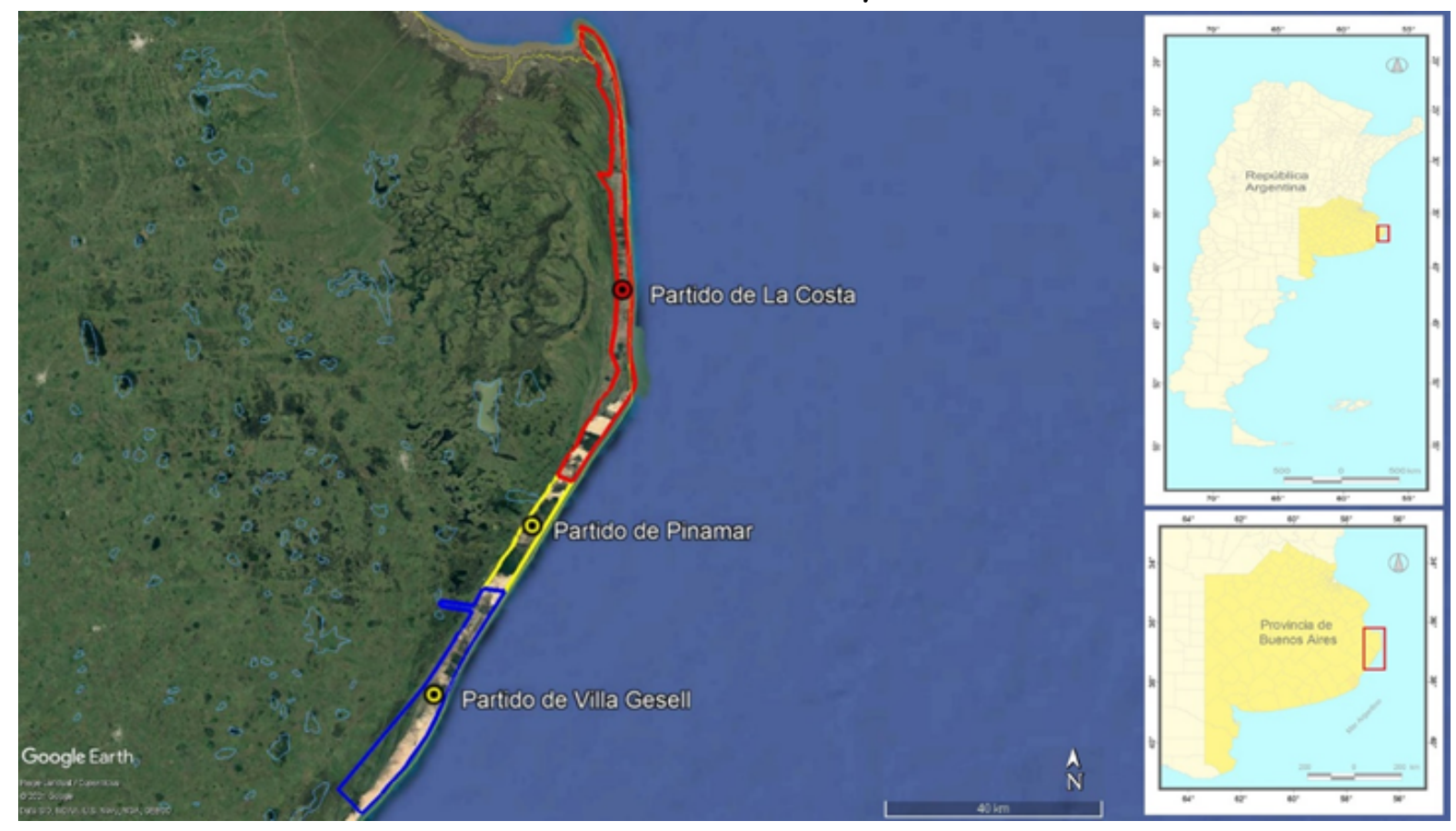

Localización geográfica de los Partidos costeros seleccionados para el presente trabajo.

Varias características en común permiten abordar y analizar el área objeto en conjunto.

Fuente: Elaboración propia a partir de imágenes satelitales disponibles en Google Earth Pro 
b) El devenir histórico: los Partidos seleccionados comparten un acontecer histórico similar. Con un origen caracterizado por la presencia de grandes terratenientes y pioneros, la exportación de ideas de trasladar playas al estilo europeo a las costas argentinas, actividades para la implantación de especies vegetales y arbóreas de distinta magnitud con la finalidad de lograr la fijación de médanos. La impronta fundacional se basó en la valoración del paisaje como recurso natural y económico.

c) Las características físico-naturales; desde el punto de vista geomorfológico, presenta dos unidades: la playa y las dunas. Las playas son rectilíneas y anchas, con pendientes suaves. Según Bértola (2006), las playas relevadas para el sector de La Costa-Pinamar-Villa Gesell, se pueden clasificar como "playas abiertas, sin cuerpos naturales de aguas de carácter permanente o transitorio que desemboquen en el mar e interfieran con la deriva litoral, ni cuerpos de almacenamiento natural tales como bañados o lagunas".

d) Con respecto al aspecto jurídico-administrativo, es de importancia señalar que comparten los mismos hitos fundacionales:

- En julio de 1978, entra en vigencia la "Ley de Municipios Urbanos". Por lo tanto, del Partido de General Madariaga surge el Municipio Urbano de La Costa. Del mismo modo, del Partido de General Lavalle nacen los Municipios Urbanos de Pinamar y Villa Gesell.

- En mayo de 1983, por medio de una nueva ley, se establece que los anteriores Municipios Urbanos pasan a ser considerados Partidos.

e) Similitud en el patrón de crecimiento poblacional; si bien no se poseen registros particulares de cada Partido anteriores a 1980, los datos de los cuatro censos realizados hasta la actualidad permiten establecer un patrón de crecimiento demográfico sostenido (Tabla N. ${ }^{\circ}$ 1). Al considerar la variación intercensal 2001-2010: Partido de La Costa (+15,9\%), Partido de Pinamar (+24,5\%) y Partido de Villa Gesell (+30,7 $\%)$, se puede determinar que dos municipios han superado el crecimiento medio provincial (13\%) en el período analizado.

TABLA N. ${ }^{0} 1$

Censos de población por municipio (1947-2025)

\begin{tabular}{|c|c|c|c|c|c|c|c|c|}
\hline Partido & 1947 & 1960 & 1970 & 1980 & 1991 & 2001 & 2010 & 2025 \\
\hline $\begin{array}{c}\text { La } \\
\text { Costa }\end{array}$ & $\begin{array}{c}\text { Sin } \\
\text { datos }\end{array}$ & $\begin{array}{c}\text { Sin } \\
\text { datos }\end{array}$ & $\begin{array}{c}\text { Sin } \\
\text { datos }\end{array}$ & 25652 & 38603 & 60483 & 69633 & 82379 \\
\hline Pinamar & $\begin{array}{c}\text { Sin } \\
\text { datos }\end{array}$ & $\begin{array}{c}\text { Sin } \\
\text { datos }\end{array}$ & $\begin{array}{c}\text { Sin } \\
\text { datos }\end{array}$ & 5326 & 10242 & 20592 & 25397 & 34182 \\
\hline $\begin{array}{c}\text { Villa } \\
\text { Gesell }\end{array}$ & $\begin{array}{c}\text { Sin } \\
\text { datos }\end{array}$ & $\begin{array}{c}\text { Sin } \\
\text { datos }\end{array}$ & $\begin{array}{c}\text { Sin } \\
\text { datos }\end{array}$ & 11632 & 16012 & 24282 & 31730 & 40812 \\
\hline
\end{tabular}

Fuente: elaboración propia sobre la base de datos del Instituto Nacional de Estadísticas y Censos (INDEC)

f) La actividad económica preponderante: el turismo de sol y playa. En el ámbito económico, el paisaje ha devenido en recurso territorial. El mismo ocupa un lugar clave en la planificación y el ordenamiento territorial. En este sentido, el paisaje se ha convertido en objeto de consumo, a partir del valor otorgado a la playa como recurso natural y económico. 
g) Desarrollo de emprendimientos urbanísticos cerrados. Puede considerarse este proceso como reciente, que encontró su desarrollo y expansión a principios del siglo XXI. Lo relevante de esta situación en común es que, después del área metropolitana de Buenos Aires, La Plata y Mar del Plata, se puede afirmar que es un sitio escogido por los desarrolladores urbanos privados para estimular el crecimiento de distintos tipos de emprendimientos cerrados (Ver Tabla N. ${ }^{\circ}$ 2).

TABLA N. ${ }^{\circ} 2$

Urbanizaciones cerradas en los Partidos de La Costa, Pinamar y Villa Gesell

\begin{tabular}{|l|c|c|c|c|}
\hline Municipios & $\begin{array}{c}\text { Cantidad de } \\
\text { urbanizaciones } \\
\text { cerradas } \\
\text { del } \\
\text { municipio }\end{array}$ & $\begin{array}{c}\text { Superficie } \\
\text { ocupada por } \\
\text { las UC }\end{array}$ & $\begin{array}{c}\text { Superficie } \\
\text { total del } \\
\text { municipio } \\
\text { ocupada por } \\
\text { UC }\end{array}$ \\
\hline La Costa & 11 & $\begin{array}{c}22600 \\
\text { has. }\end{array}$ & 3390 has. & $15 \%$ \\
\hline Pinamar & 7 & 6300 has. & 2882 has. & $45 \%$ \\
\hline Villa & 6 & $\begin{array}{c}28500 \\
\text { has. }\end{array}$ & 1558 has. & $6 \%$ \\
\hline
\end{tabular}

Fuente: Elaboración propia

Para concluir este primer apartado, es importante destacar que el área de estudio, como cualquier ciudad turística del mundo, experimenta una notable variación entre la cantidad de habitantes estable y la estacional. Debido al incremento poblacional se hace necesario generar una mayor oferta de bienes y servicios en los períodos de vacaciones o fines de semana largos. Asimismo, este aumento demográfico deviene en una serie de impactos territoriales negativos debido a la magnitud de las demandas generadas por la población.

\section{Metodología, FUentes de INFORMACión y OBJETivos}

Para la realización del presente estudio, se emplearon distintas técnicas que permitieron abordar la problemática y el área objeto de estudio, a partir de distintos enfoques:

a) Recopilación bibliográfica referente al área y el problema objeto de estudio.

b) Elaboración de mapas y cartografía, con la utilización de Google Earth. De este modo, las imágenes presentadas desde sensores remotos ofrecen gran detalle para: a) la delimitación de los Partidos de La Costa, Pinamar y Villa Gesell; b) la localización de los principales emprendimientos urbanos cerrados desarrollados en el espacio litoral de los municipios mencionados.

c) Empleo del análisis geohistórico para analizar la evolución espacial y temporal del área objeto de estudio. Por cuestiones metodológicas, se hizo necesario identificar hechos (relacionados con acontecimientos locales, provinciales y nacionales) que sirvieran de corte y enlace de un momento histórico a otro. 
Por todo lo expuesto, el trabajo persigue una serie de objetivos que se describen a continuación:

- Realizar una aproximación a las características de ocupación del territorio costero en los Partidos de La Costa, Pinamar y Villa Gesell.

- Utilizar el análisis geohistórico para indagar los cambios y continuidades en el espacio mencionado.

- Establecer una relación entre la evolución geohistórica del espacio mencionado y el proceso de litoralización.

- Enumerar y caracterizar los principales emprendimientos urbanos privados que se desarrollaron en el espacio determinado.

- Comunicar sobre la situación actual de los municipios objeto de estudio para orientar acciones conducentes a un manejo integral de las áreas costeras como herramienta de gestión.

El trabajo contiene la siguiente hipótesis: el espacio litoral de los Partidos de La Costa, Pinamar y Villa Gesell se encuentra bajo un proceso de litoralización. Si las autoridades municipales no toman medidas que propongan un manejo integrado de dicho espacio para una gestión planificada, la misma devendrá en una progresiva degradación del espacio litoral estudiado.

\section{Marco TEÓRICo}

Para el desarrollo del presente trabajo, es imprescindible realizar un recorrido teórico sobre los conceptos y los procesos centrales que guiaron el artículo. Para ello, es importante destacar que las áreas litorales han constituido a lo largo de la historia un ámbito favorable para el asentamiento de la población por las actividades humanas. Los espacios costeros mundiales se poblaron en épocas remotas y sirvieron como fuente de abastecimiento y vía de navegación. La población mundial ha crecido de manera tal que "en la actualidad aproximadamente el $40 \%$ vive a menos de 60 kilómetros de la costa" (PNUMA, 2004).

Además, por razones históricas, "el origen de la expansión urbana de la región americana se sitúa en la franja litoral” (Barragán Muñoz, 2012, p. 12). Este patrón de ocupación del territorio se remonta a la época colonial, periodo en el que la costa era un ámbito geográfico estratégico para la vinculación con las antiguas metrópolis, lo que explica una "elevada concentración de la población, de la actividad económica y, por tanto, de las ciudades” (UN-Hábitat, 2010, p. 11). En consecuencia, esta combinación de factores origina un aumento en las presiones ejercidas sobre el litoral. Por lo tanto, se precisan mecanismos de gestión integrada para hacer frente a los problemas ecológicos y socioeconómicos que puedan llegar a surgir.

En líneas generales, el concepto de litoral puede definirse como el área de transición entre los sistemas terrestres y los marinos. La costa constituye un ambiente único, de interfase, en el cual confluyen procesos y dinámicas tanto de origen continental o terrestre, como atmosférico, o marino. En la misma se desarrollan fenómenos de origen físico y biológico, los cuales generan microambientes diversos y delicados resultantes de la convergencia de múltiples variables (Martínez, s/f). Concretamente, D’Amico lo señala como

la zona de interrelación entre materialidades y dinámicas acuáticas y terrestres; los límites de injerencia de cada una son difusos, y su delimitación dependerá del objeto de estudio. En dicha zona, ambos medios interactúan en una zona de interposición efectiva; ello da lugar a procesos de erosión y sedimentación, que producen, de esta manera, distintas formas litorales: playas, acantilados, dunas, etc. (D’Amico, 2009, p. 170).

Barragán Muñoz (2003) define al área litoral como "la franja de anchura variable, resultante del contacto interactivo entre la Naturaleza y las actividades humanas que se desarrollan en ámbitos que comparten la existencia o la influencia del mar". De este modo establece tres subáreas bien definidas por sus características físico-naturales: "la marítima, la terrestre y la que podría denominarse anfibia o marítima-terrestre".

Por ello, no es desacertado afirmar que la degradación del espacio costero constituye una problemática a nivel mundial, como resultado de la intensa presión al cual este se encuentra sometido. En el caso de 
los municipios estudiados, se puede indicar una serie de causas que pueden fundamentar la afirmación precedente. A saber:

a) El turismo, principal actividad económica del área, supone una visión dual y complementaria del territorio, en tanto objeto de consumo y soporte de dicha actividad. Así, se convierte en un "objeto para el ocio" aprovechando y potenciando sus características naturales y/o modificadas, mientras que considerarlo como soporte de la actividad turística implica transformar ese territorio según el perfil turístico que se persiga, a través de la instalación de infraestructura y equipamientos (D’Amico, 2009). El acondicionamiento turístico exige la puesta en valor del recurso natural y origina la construcción de equipamiento específico para brindar servicios de alojamiento, transporte y recreación, así como servicios complementarios e infraestructura de base a fin de asegurar la accesibilidad al sitio (Benseny, 2008).

El valor escénico dado por la sucesión de playas y las extensas zonas aptas para baños, han constituido factores que han conducido a intensas presiones. En ellas, han predominado los intereses económicos vinculados al desarrollo turístico y a los emprendimientos inmobiliarios;

b) La concentración de población en estrechas franjas de terreno está asociada a las particularidades del relieve (áreas de bosques de coníferas, conjunto de dunas, diversidad en las pendientes del terreno). Estas características dificultan un incremento de la mancha urbana ordenado y estimulan un crecimiento urbano disperso. Vinculado con lo anteriormente mencionado, la actividad turística acentúa, aún más, la problemática poblacional. Por un lado, crece la población estable debido a la oferta de trabajo. Y por otro, "convoca a gran cantidad de turistas, en mayor medida provenientes del turismo interno, que provoca que casi se duplique en época estival” (Mantecón, 2013, p. 123).

c) El crecimiento y expansión de emprendimientos urbanos cerrados en el área objeto de estudio. En este sentido, es de destacar que las actividades en la industria de la construcción desde 2003 en adelante han presentado un ritmo sostenido en los municipios de Villa Gesell y Pinamar que son los que presentan los mayores porcentajes de crecimiento por afluencia migratoria. La incidencia de desarrollos urbanos de carácter privado va avanzando, captando una demanda que busca exclusividad y confort. De tal forma que, "superada la crisis económica y política de 2001, los emprendedores inmobiliarios re-direccionaron su oferta hacia las áreas con alto valor paisajístico y la costa atlántica se ha convertido en uno de sus principales objetivos" (Vidal-Koppmann, 2015, p. 106). A modo de ejemplo del impacto que tienen estos emprendimientos urbanos sobre el espacio litoral, se puede mencionar la localidad privada de Costa Esmeralda, ubicada en el municipio de La Costa. No se trata de un barrio sino de una urbanización especial con una extensión de 1.000 hectáreas, compuesta por áreas residenciales y deportivas que incluyen canchas de polo y de golf y que, además, abarca tres kilómetros de la costa marítima (Figura N. ${ }^{\circ} 2$ ).

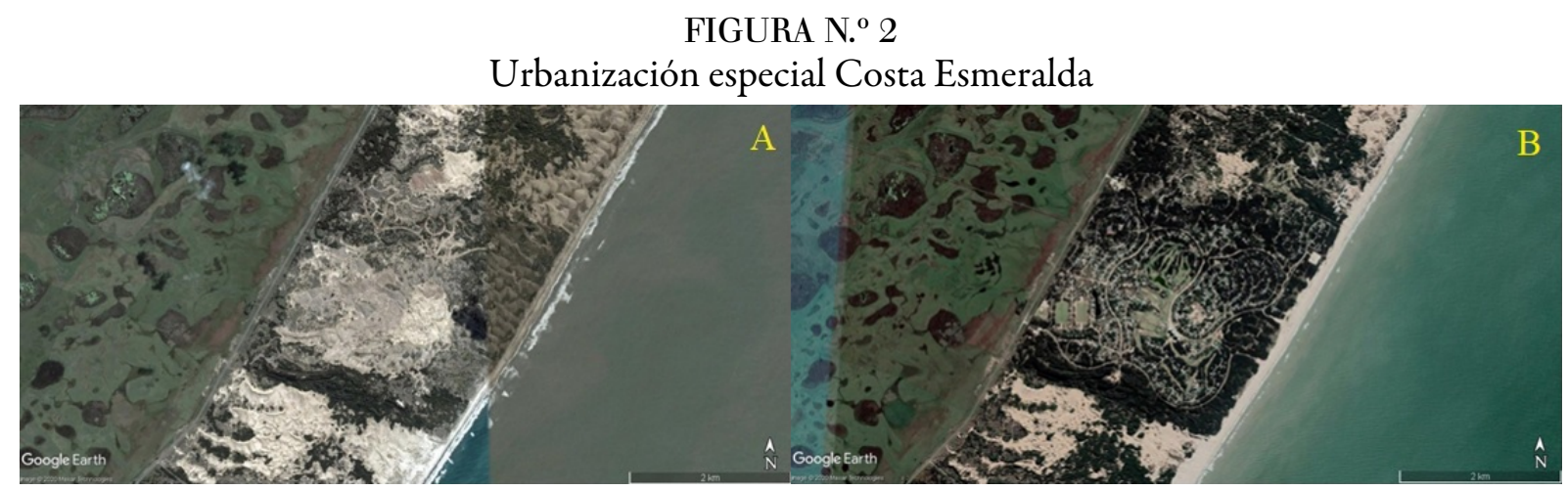

Cambios en el uso del suelo por urbanizaciones privadas. a) Superficie para 2006 que ocupa el emprendimiento privado Costa Esmeralda; b) Superficie ocupada por Costa Esmeralda en 2020. 
A continuación, es importante definir un proceso que reviste singular importancia y que involucra directamente al espacio litoral: el concepto de litoralización. De forma general, se puede definir como el proceso caracterizado por la confluencia del crecimiento demográfico, las actividades económicas asociadas al ámbito litoral y las presiones detectadas sobre dicho espacio (Barragán Muñoz, 2003). Esta tendencia de sobreutilización costera resulta poco deseable desde la óptica de la sostenibilidad ambiental. Con lo descripto, es posible encontrar relación entre el área objeto de estudio y dicho proceso. Siguiendo esta línea, Zdruli (2008) sugiere que "el mejor camino para tratar la litoralización [del territorio] es aplicar los principios de la Gestión Integrada de Zonas Costeras” (Zdruli, 2008, p. 8). El espacio litoral costero es escenario de un conjunto de tensiones y conflictos que ponen de manifiesto la necesidad de generar una política de manejo integral de tales áreas que mejore su gestión.

Por último, para llevar adelante la presente investigación, se utilizó la técnica del análisis geohistórico para observar la evolución espacio/temporal del área objeto de estudio hacia el proceso de litoralización. El enfoque geohistórico se desprende de la propia concepción geográfica que entiende al "espacio como producto concreto o síntesis de la acción de los grupos humanos sobre el ambiente para su necesaria conservación y reproducción, sujeto a condiciones históricas determinadas" (Tovar, 1984). El hecho de recurrir al tiempo solo como un factor explicativo y no como parte inherente del espacio es fuente de un equívoco singular: considerar al espacio como un escenario en el cual transcurren hechos (Tomadoni, 2007).

Tiempo y espacio son una unidad para el análisis de las problemáticas sociales. En efecto, el espacio es proceso, es cambio y, por lo tanto, no puede entenderse de manera estática. Es una instancia dinámica, es pura acción y mutación de su naturaleza original, en nuevas formas espaciales o nuevas naturalezas que se construyen a través del tiempo (Santos, 1996a, p. 66; Santos, 1996b, p. 12).

Asimismo, Tomadoni sugiere que "la periodización de los procesos sociales es un recurso analítico de los científicos sociales, pues permite dar cuenta de permanencias y transformaciones durante un considerable fragmento de tiempo" (Tomadoni, 2007, p. 58).

\section{Análisis geohistórico aplicado a los Partidos de la Costa, Pinamar y Villa GESELL}

Para comprender el proceso que originó esos espacios costeros es importante analizar su evolución en el contexto histórico. Es necesario destacar que el estudio se fundamenta, paralelamente, en dos enfoques: por un lado, el sincrónico, en el cual se realiza el análisis de una situación o proceso en un momento dado, pero en distintos espacios; por otro lado, el diacrónico, es decir, la realización de cortes históricos para observar cómo va evolucionando un mismo espacio a lo largo del tiempo. Generalmente, este último enfoque está orientado hacia un solo punto a lo largo del tiempo, pero, en esta ocasión, se focaliza en un área de estudio que presenta varias características generales en común.

Bertoncello (1992) afirma que estos pueblos tienen un origen modesto, ya que sus "fundaciones" consisten en meros trámites administrativos a fin de cumplir con la Ley N. 3487 de Fundación de Pueblos vigente en la provincia de Buenos Aires desde 1913. La misma estipulaba que la creación de nuevos pueblos debía ser aprobada por la Dirección de Geodesia y Catastro provincial, la que debía constatar que el sitio reuniese las cualidades necesarias (con agua potable, no inundable) y que se proveyera la cesión al fisco de las tierras para usos públicos, requisitos comunes a cualquier pueblo de la provincia, que no tenían en cuenta ni el particular destino "recreativo" ni la topografía específica de los balnearios.

Por lo tanto, en relación con el aspecto temporal, se realiza un recorte que abarca todo el siglo XX y finaliza en la segunda década del siglo XXI. Con respecto al ámbito espacial, el estudio se limita a los Partidos de La 
Costa, Pinamar y Villa Gesell. Dicha determinación permitió representar la evolución espaciotemporal en tres períodos:

- La primera etapa se fundamenta en la edificación de las primeras construcciones, pioneros, fijación de los médanos y las tareas de forestación con especies exóticas (1900-1940).

- Una vez estabilizado el movimiento de arena, surge la idea de urbanizar y comienza la segunda etapa basada en el fomento del turismo, la urbanización y la fundación de ciudades y Partidos (1941-1983).

- Por último, el tercer periodo comienza con la creación de los Partidos, el valor otorgado a la playa como recurso natural y económico (1983-2020).

\subsection{Primer período (1900-1940): edificación de las primeras construcciones, pioneros, fijación de los médanos y tareas de forestación}

El presente período puede ser caracterizado como el origen de las principales localidades que se ubican en el área de estudio y las diferentes labores de forestación de espacios vegetales y arbóreas con la finalidad de obtenerla fijación de los médanos. Por ese entonces, la zona costera formaba parte de las estancias agropecuarias cuyos fondos llegaban hasta la playa (Elicabe, 2008). En esta línea,

la valorización del ecosistema y su funcionalización se dio cuando, a principios del siglo XX, se puso de moda ir a bañarse al mar en los veranos en los cuales toda la familia, parientes y amigos disfrutaban de las playas, el paisaje y el clima (Verón, 2006, p. 11).

Dadon sostiene que "el emplazamiento de nuevas localidades en los campos de médanos resultó un gran desafío para los arquitectos y los urbanistas. No había demasiadas experiencias previas en el país, ni en el mundo" (Dadon, 2005, p. 57).

En el año 1908 llegaron al actual Pinamar los belgas Fernando Robette y Agustín Poli para comprar tierras con el objetivo de proyectar una sofisticada ciudad balnearia con el mismo modelo de aquella ciudad de origen belga cuyo nombre, Ostende, significa "Fin del Este" (Bohmer, 2012). Para concretar sus proyectos se construye un muelle y el Hotel Termas; ese mismo año también se comienza la construcción de la Rambla Sur. En abril de 1913, se celebra la ceremonia de fundación de la nueva ciudad y se produce una importante campaña publicitaria para promocionar la venta de los lotes. No obstante, la Primera Guerra Mundial impidió que el gran proyecto continuara con el ritmo necesario y surgieron las dificultades. Las fuertes sudestadas provocaron el abandono de las obras. Sin embargo, en los últimos años de la década del 30, el arquitecto Jorge Bunge se asocia con Valeria Guerrero, dueña de las tierras, y ambos conforman una sociedad. Bunge crea un diseño urbano tan particular como novedoso, trazando las calles en forma de arabescos y curvas para respetar las dunas y ondulaciones del paisaje (Municipalidad de Pinamar, 2020). Y en la franja costera de estas tierras se formaron también las localidades de Cariló y Valeria del Mar. Así comienza la fijación de los médanos, apertura de calles y las primeras construcciones para hospedar a los visitantes (Figura N. ${ }^{\circ} 3$ ).

El devenir de Villa Gesell está ligado a la figura de su fundador: Carlos Idaho Gesell. Hacia 1931 adquirió terrenos costeros entonces considerados inútiles. Sobre todo, por hallarse cubiertos de dunas entre las que solo se aventuraba el ganado cimarrón. Gesell era un comerciante dedicado a la fabricación y venta de muebles. Para asegurarse el abastecimiento de madera, decidió forestar un amplio campo de médanos localizado en la costa marítima bonaerense (Municipalidad de Villa Gesell, 2020). Durante diez años realizó una fuerte inversión en diferentes especies de flora exótica capaces de resistir las condiciones del lugar, lo que le originó serios problemas económicos y su alejamiento del negocio familiar (Gesell, 1983). 
FIGURA N. ${ }^{\circ} 3$

Fijación de médanos en el actual Partido de Pinamar y Villa Gesell

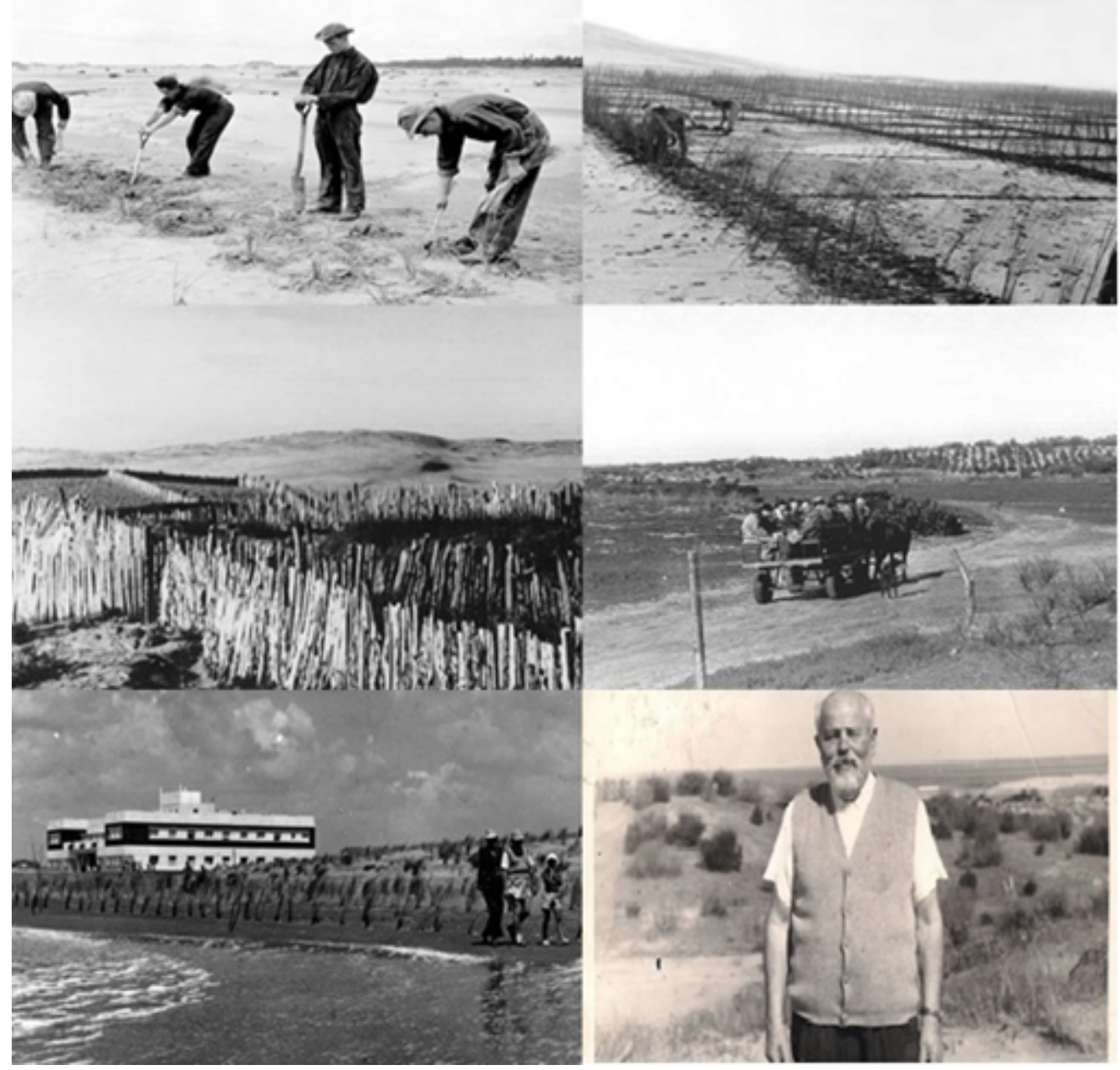

Las imágenes pertenecen a las tareas de fijación de médanos llevadas adelante en un sector del área objeto de estudio. Sobre el margen derecho inferior una fotografía de uno de los pioneros de la región, Carlos Idaho Gesell.

Fuente: https://www.voyagesell.com.ar/ y https://www.pinamarturismo.com.ar/

A diferencia de Pinamar y Villa Gesell, en el actual Partido de La Costa considera a 1934 como el año donde se introduce el turismo en la zona. Según Elicabe (2008), un grupo de pobladores de Gral. Lavalle formaron la sociedad "Unión y Progreso de Ajó" y es a quienes se considera como pioneros del turismo en el Partido. Esta sociedad se pone en contacto con el Automóvil Club Argentino, que en 20 hectáreas instala un grupo de carpas para realizar sus primeras excursiones, llegando de esta forma los primeros turistas (Elicabe, 2008). En 1935 se fundan las localidades de San Clemente y Mar de Ajó. Con el paso del tiempo surgen otras localidades.

\subsection{Segundo período (1941-1983): turismo, urbanización y la fundación de ciudades y Partidos}

El segundo periodo presenta tres particularidades. La primera de ellas está vinculada a una continuidad en la fundación de distintas ciudades costeras y la estimulación de los municipios para poblar estos nuevos espacios (Elicabe). En sentido cronológico surgieron las siguientes urbanizaciones turísticas: Villa Gesell (1931), Mar de Ajó (1934), San Clemente del Tuyú (1935), Pinamar (1941), San Bernardo (1943), Valeria del Mar 
(1945), Mar del Tuyú (1945), Santa Teresita (1946), Mar Azul (1946), Las Gaviotas (1948), La Lucila del Mar (1954), Mar de las Pampas (1957), Cariló (1960), Las Toninas (1960), Costa del Este (1966) y Aguas Verdes (1966). En segundo lugar, las consecuencias del proceso de ocupación de las costas iniciado en la década del 40 comenzaron a percibirse recién dos décadas más tarde. Según Dadon,

las mejoras en las rutas de acceso y los medios de transporte masivos, la incipiente prosperidad de las clases medias y los beneficios sociales para las clases trabajadoras incrementaron la demanda de nuevos destinos y el crecimiento de los centros turísticos ya existentes (Dadon, 2005, p. 62).

Por último, este periodo concluye con una serie de decretos legislativos, promulgados por el gobierno provincial, que determinan la creación de los tres partidos que son abordados en el actual estudio.

A partir de la década de 1930, la afluencia turística hacia la ciudad de Mar del Plata fue incrementándose hasta posicionarla, en los años 40, como el principal destino turístico costero del país gracias al desarrollo del denominado turismo de masas (Bouvet, Desse, Morrell y Villar, 2005). Una serie de obras (pavimentación, en 1938, de la ruta provincial N. 2 Buenos Aires - Mar del Plata) y nuevas costumbres (en relación a la difusión del automóvil) permitieron conocer a la ciudad como la "ciudad feliz, de todos y para todos" (Mantobani, 2002). En el caso de los partidos que son objeto de estudio, la apertura de los balnearios a los sectores urbanos medios estuvo vinculada al también denominado "turismo social", que se inició con el primer gobierno peronista. Sumado a lo anterior, Ordoqui y Hernández (2009) califican a la segunda etapa del turismo de sol y playa como Turismo Masivo. De esta manera, a partir de los años sesenta comienza a cobrar mayor importancia el hábito de hacer turismo entre capas cada vez más amplias de la población.

El 14 de febrero de 1943 se inaugura Pinamar como balneario y poco después se aprueba el Plan Director de Urbanización presentado por el arquitecto Jorge Bunge. Unos años después llega el tren a Pinamar y se crea el camino entre Pinamar y Madariaga. En la misma década, Valeria Guerrero decide crear su propia villa turística sobre terrenos que eran de su propiedad, se funda la localidad de Valeria del Mar, se realiza la fijación de médanos, se foresta la zona con muchas acacias y, en 1960, se realiza el primer loteo (Municipalidad de Pinamar, 2020). El proyecto original era hacer un balneario en el que el verde de la naturaleza y el azul del mar formaran un armonioso conjunto. En sociedad con Guerrero, Bunge funda una empresa llamada Pinamar S. A.

En Villa Gesell, hacia 1944, se construyeron los primeros hoteles. En 1956 la empresa de transportes Antón inicia sus servicios de Buenos Aires a la Villa con lo cual se intensifica la llegada de turistas al balneario (Municipalidad de Villa Gesell, 2020). En la década del 70 aparecen los edificios de propiedad horizontal, los dúplex y todo tipo de viviendas colectivas que le dan otras características a la ciudad. Para la construcción de estos edificios "se extrae arena de la playa y comienza el avance urbanístico sobre la barrera medanosa. La localidad crece sin una planificación que estructure la expansión urbana, prevea espacios públicos y la prestación de infraestructura" (Manzano y Velázquez, 2018, p. 234). Según Benseny, "el crecimiento urbano se intensificó especialmente en los primeros 300 metros de la línea de costa y en los sectores céntricos de la ciudad, sobre terrenos ocupados por los médanos" (Benseny, 2012, p. 20). La superficie construida "aumentó la impermeabilidad del suelo y en consecuencia los flujos superficiales evacúan directamente hacia la playa" (Gesell, 1983; Masor, 1995).

En el actual Partido de La Costa, en 1945, Juan José Cacace solicita la aprobación de un fraccionamiento, es decir, una ampliación de Mar del Tuyú. En enero de 1946 el Gobierno dicta el decreto de subdivisión de tierras con el nombre de Santa Teresita "Jagüel del Medio". La superficie total es de 500 hectáreas (Municipalidad de La Costa, 2020). Según Bertoncello (1992), de todas las fundaciones el denominador común fue el "considerar el medio natural como un obstáculo que debía ser vencido, para que se amoldara a un plano urbano dibujado en un tablero ante una superficie irregular y movediza”. Asimismo, la forestación era sumamente costosa por varios motivos: a) el tiempo que las plantas requerían para adaptarse al medio; b) el castigo que recibían del viento hostil; y c) el periodo que requería la fijación de un médano. 
En síntesis, el común denominador de los Partidos abordados se dio en el marcado crecimiento de estos núcleos urbanos ante las demandas del turismo interno, imponiendo mayor presión sobre estos ambientes costeros (Morello, 1983). Esta etapa se caracterizó por la valorización del espacio litoral como proveedor de servicios culturales (turismo y recreación) y de abastecimiento (extracción de arena). Así, se privilegió construir (con arena extraída de las playas) edificaciones lo más cercanas posible a la línea de costa destinadas al turismo, en detrimento de los servicios de regulación morfosedimentaria o de las perturbaciones naturales. Ello dio origen a problemáticas de erosión costera por la pérdida y alteración del servicio (Dadon, 2003; Isla, 2010; Verón, 2014).

En el contexto anteriormente desarrollado, el gobierno de la provincia de Buenos Aires reconoce la evolución de estas ciudades: por consiguiente, el 11 de junio de 1978 establece mediante la Ley N. ${ }^{\circ} 9024$ la creación de "Municipios Urbanos". Del mismo surgen los municipios turísticos: De la Costa, Pinamar, Villa Gesell y Monte Hermoso. El Municipio Urbano de La Costa comienza a funcionar en forma independiente de General Lavalle el 1. ${ }^{\circ}$ de Julio de 1978 con cabecera en la localidad de Mar del Tuyú. Mientras que los municipios Urbanos de Pinamar y Villa Gesell comienzan a funcionar de manera autónoma del Partido de General Madariaga en la fecha mencionada con anterioridad.

\subsection{Tercer período (1983-2020): creación de los Partidos, valor otorgado a la playa como recurso natural y económico}

Este periodo comienza con una serie de dificultades jurídicas que surgen con motivo de las elecciones, por no poder encuadrarse los "Municipios Urbanos" en la ley electoral de mayo de 1983. A partir de ello se promulga la Ley 9949. La misma establece que los municipios se convierten en Partidos y eligen su primer gobierno por elecciones democráticas en octubre de 1983. Y presenta como cierre (por cuestiones metodológicas, solamente) un creciente proceso de privatización del territorio reflejado en el incremento de barrios cerrados. Se caracteriza por ser un fenómeno residencial consolidado en áreas metropolitanas del país, pero en constante crecimiento y expansión en las ciudades intermedias y pequeñas del país.

Durante la década de los noventa, la actividad turística se vio notablemente mermada por influencia del contexto nacional. Las clases adineradas eligieron preferentemente los destinos internacionales para sus vacaciones y las clases de menores recursos se vieron afectadas de manera creciente por el desempleo. Dadon (1999) sostiene que numerosos municipios enfrentaron problemas financieros, de modo que, en este período, se agudizaron los problemas ambientales, agravados por negligencia previa: déficit en las reservas de agua potable, minería ilegal de arena, contaminación, deterioro estético, entre otros (Dadon). En las localidades del Partido de La Costa, un distrito históricamente visitado por clases medias trabajadoras, disminuyó la afluencia turística. En los partidos de Pinamar y Villa Gesell se manifestó una diferencia entre sus localidades. Ciertas ciudades (como Mar de las Pampas y Cariló) se "orientaron hacia las clases media alta y alta, al proponer un turismo alternativo que privilegiara el contacto con la naturaleza y el descanso" (Verón, 2012, p. 10).

Con respecto a la situación demográfica, los Partidos de La Costa, Pinamar y Villa Gesell fueron los de mayor crecimiento poblacional con respecto al resto de los partidos de la Provincia de Buenos Aires. Durante el periodo 1991-2001, la variación porcentual relativa es muy superior al promedio provincial. Esta tendencia se acentúa en el siguiente periodo 2001-2010, pues supera nuevamente el promedio de la provincia (Tabla N. $\left.{ }^{\circ} 3\right)$. 
TABLA N. ${ }^{\circ} 3$

Variaciones intercensal por municipio (1970-2010)

\begin{tabular}{|c|c|c|c|c|}
\hline Municipio & $1970 / 80$ & $1980 / 91$ & $1991 / 01$ & $2001 / 10$ \\
\hline La Costa & Sin datos & $50,5 \%$ & $56,7 \%$ & $15,1 \%$ \\
\hline Pinamar & Sin datos & $93,7 \%$ & $100,3 \%$ & $24,5 \%$ \\
\hline Villa Gesell & Sin datos & $37,7 \%$ & $51,6 \%$ & $30,7 \%$ \\
\hline $\begin{array}{c}\text { Total Provincia de } \\
\text { Buenos Aires }\end{array}$ & $23,8 \%$ & $15,9 \%$ & $9,8 \%$ & $10,6 \%$ \\
\hline
\end{tabular}

Fuente: elaboración propia sobre la base de datos del Instituto Nacional de Estadísticas y Censos (INDEC)

Esto implicó una fuerte urbanización de la zona costera, resumido en el aumento de las viviendas y el incremento de los proyectos de los modelos de barrios privados. Hacia fines de los 90 se produjo una crisis económica de la Argentina. La crisis social y la devaluación económica dificultaron el turismo hacia el exterior. En este contexto, los desarrolladores urbanos realizan inversiones en las localidades ubicadas sobre la costa atlántica. Junto al Área Metropolitana de Buenos Aires, las ciudades intermedias de La Plata y Mar del Plata son los mayores ejemplos de un modelo de urbanización cerrada que encuentra su auge en este periodo (Frediani, 2008 y 2009; Frediani y Matti, 2007; Maya, 2017, 2018 y 2019). Con respecto al área objeto de estudio, a partir del año 2003, este proceso toma una intensidad mayor a la que había alcanzado en la década anterior (Tabla N. ${ }^{4}$ ). 
TABLA N. ${ }^{\circ} 4$

Emprendimientos urbanos cerrados en los Partido de La Costa, Pinamar y Villa Gesell (2020)

\begin{tabular}{|c|c|c|c|}
\hline Partido & Emprendimiento & Tipología & $\begin{array}{l}\text { Superficie } \\
\text { (en has.) }\end{array}$ \\
\hline \multirow{11}{*}{$\begin{array}{c}\text { La } \\
\text { Costa }\end{array}$} & El Descanso & Barrio cerrado & 7 \\
\hline & $\begin{array}{l}\text { Pueblo Marítimo Punta } \\
\text { Médanos }\end{array}$ & $\begin{array}{l}\text { Urbanización } \\
\text { especial }\end{array}$ & 79 \\
\hline & $\mathrm{Km} 314$, Casas de Mar & Club de campo & 30 \\
\hline & Jagüel del Medio & Megaemprendimiento & 125 \\
\hline & Costayres & Barrio cerrado & 50 \\
\hline & $\begin{array}{l}\text { EcoParque } \\
\text { Campos de Mar }\end{array}$ & Barrio cerrado & 25 \\
\hline & Ángeles del Mar & Club de chacras & 296 \\
\hline & Villa Robles & Barrio cerrado & 1100 \\
\hline & North Beach & Barrio cerrado & 278 \\
\hline & Costa Esmeralda & Club de chacra & 1000 \\
\hline & $\begin{array}{l}\text { Dunas de Pinamar } \\
\text { Village }\end{array}$ & Megaemprendimiento & 400 \\
\hline \multirow{7}{*}{ Pinamar } & La Herradura & Club de campo & 110 \\
\hline & Laguna El Rosario & Barrio cerrado & 1500 \\
\hline & Pioneros & Barrio cerrado & 28 \\
\hline & Pinamar Chico & Barrio cerrado & 7 \\
\hline & Chacras Dos Montes & Club de chacras & 270 \\
\hline & Dríades & Country del Mar & 700 \\
\hline & Terrazas al Golf & Barrio cerrado & 5 \\
\hline \multirow{6}{*}{$\begin{array}{l}\text { Villa } \\
\text { Gesell }\end{array}$} & Country Hipocampo & Barrio cerrado & 6 \\
\hline & EI Salvaje & Club de chacra & 350 \\
\hline & Dunas de las Pampas & Club de campo & 20 \\
\hline & Chacras del Mar & Club de campo & 60 \\
\hline & $\begin{array}{l}\text { Country Club San } \\
\text { Alfonso }\end{array}$ & Megaemprendimiento & 538 \\
\hline & Port Dora & Megaemprendimiento & 557 \\
\hline
\end{tabular}

Fuente: Elaboración propia en base a la tipología de Vidal-Koppmann (2014). 
Frente a este presente urbano, es importante describir las características socioterritoriales de los principales emprendimientos inmobiliarios y, a su vez, analizar brevemente algunas particularidades que presenta el área de estudio.

- En primer lugar, en el sur del Partido de La Costa, se emplazan tres megaemprendimientos: Costa Esmeralda, North Beach y Villa Robles (Figura N. ${ }^{0}$ ). En conjunto, reúnen casi 3500 hectáreas de ocupación territorial. A pesar de haber diferencias en cuanto al porcentaje de asentamiento poblacional, es factible confirmar que son tres emprendimientos pujantes en su desarrollo. El entorno natural, caracterizado por la cercanía al mar, la presencia de dunas y el bosque, son elementos que los desarrolladores urbanos han potenciado a través del marketing publicitario. Costa Esmeralda fue creado en 2004 y tiene 1694 viviendas construidas, 224 en marcha y 105 departamentos (Eidico, 2021). Es el barrio privado más grande de la zona. Durante los meses de verano tiene una población estimada en 12.000 habitantes (Horvat, 2021). El lugar tiene su transporte interno y un sistema propio de recolección de residuos. Sin embargo, su cercanía a Pinamar le valió cierto resentimiento por parte de algunos habitantes de esa ciudad. Costa Esmeralda es un proyecto que está en proceso, por lo tanto, aún no está terminado ni aprobado el catastro. Dada esta circunstancia, por ejemplo, ante cualquier emergencia, se suelen usar los servicios de Pinamar. En paralelo, North Beach y Villa Robles presentan similitudes con la urbanización vecina: edificios frente al mar, lotes que van de los 800 a los 2400 metros cuadrados, áreas deportivas con canchas de fútbol, tenis, paddle, básquet, vóley, rugby y golf, además de vestuarios, pileta climatizada y un Club House (Content LAB, 2021). Asimismo, en Villa Robles está planificada la construcción de dos helipuertos y una pista de aterrizaje para aviones privados (Villa Robles, 2021).

FIGURA N. ${ }^{\circ} 4$

Costa Esmeralda, North Beach y Villa Robles.

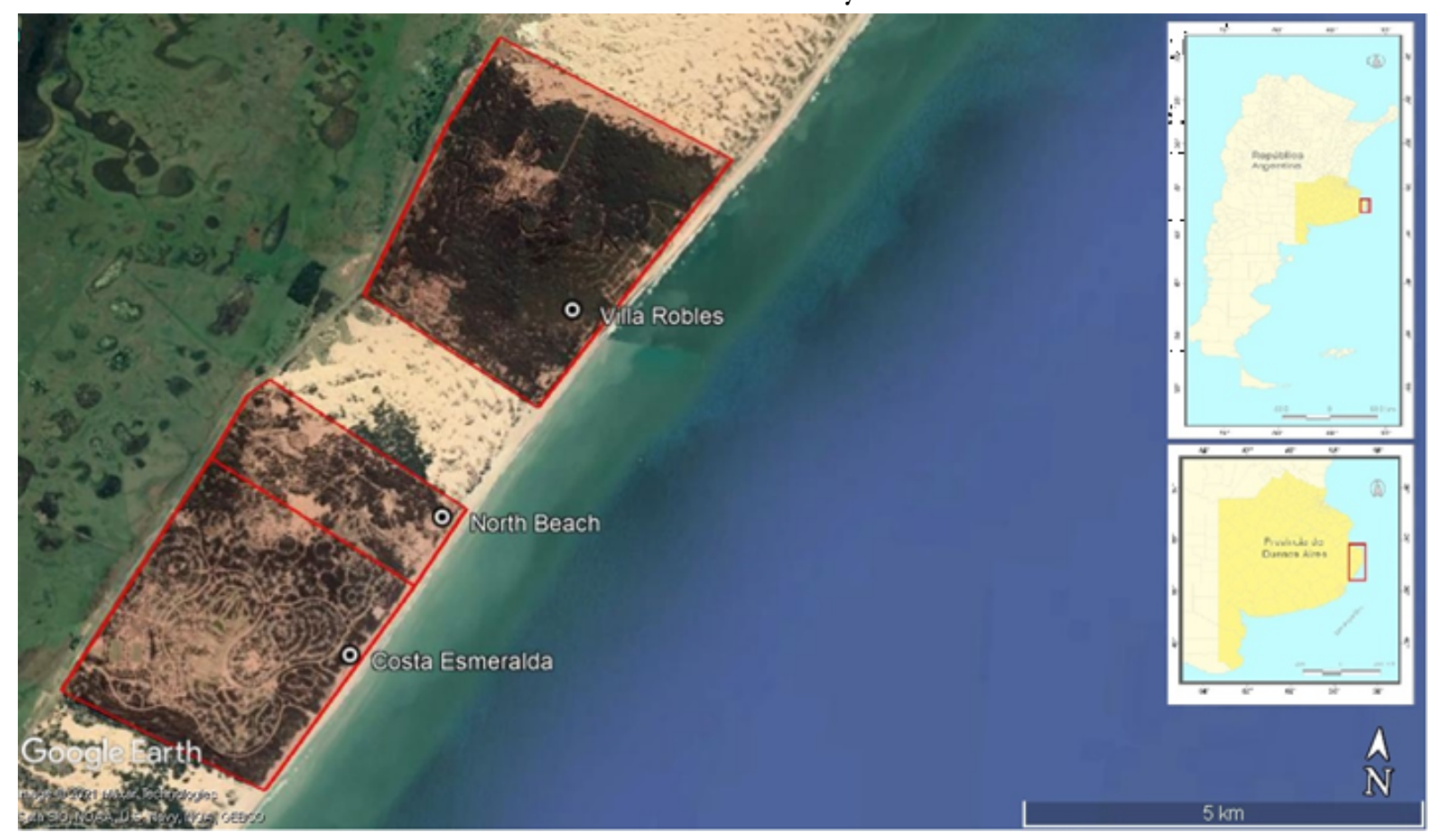

Los principales emprendimientos urbanos cerrados del Partido de La Costa. Fuente: elaboración propia a partir de Google Earth.

- En segundo lugar, cercanos al núcleo urbano fundacional de Pinamar, se sitúan los barrios cerrados de La Herradura, Pioneros y Pinamar Chico (Figura N. ${ }^{\circ}$ 5). En este caso, lo destacado no es su extensión 
territorial, sino la participación de una empresa perteneciente al municipio como principal promotora de este tipo de urbanizaciones: Pinamar S. A. Esta compañía es la desarrolladora inmobiliaria más importante de la localidad, en cuya diversificación edilicia se puede mencionar distintos tipos de inversión: lotes residenciales (Pinamar Norte, Islas del Golf y Álamos II), macrolotes (Náyades y Pinamar Norte), canchas de golf (Links de Golf Pinamar), gran pluralidad en servicios de hotelería, desarrollo de paradores y balnearios exclusivos, junto a la promoción de barrios cerrados (Pinamar S.A., 2021). Sobre la ruta 11 se encuentra La Herradura, que cuenta con 250 lotes y cancha de polo. Lindando a este se localiza Pioneros, de 28 hectáreas. Ambos emprendimientos ponen mayor énfasis en el cuidado del medioambiente, cuyas premisas son parte del reglamento interno. Cabe destacar que, en línea con las urbanizaciones mencionadas, Pinamar S.A. ha plantado cerca de 6 millones de árboles con la finalidad de formar una verdadera ciudad jardín frente al mar (Pinamar S.A., 2021).

FIGURA N. 5

La Herradura, Pioneros y Pinamar Chico

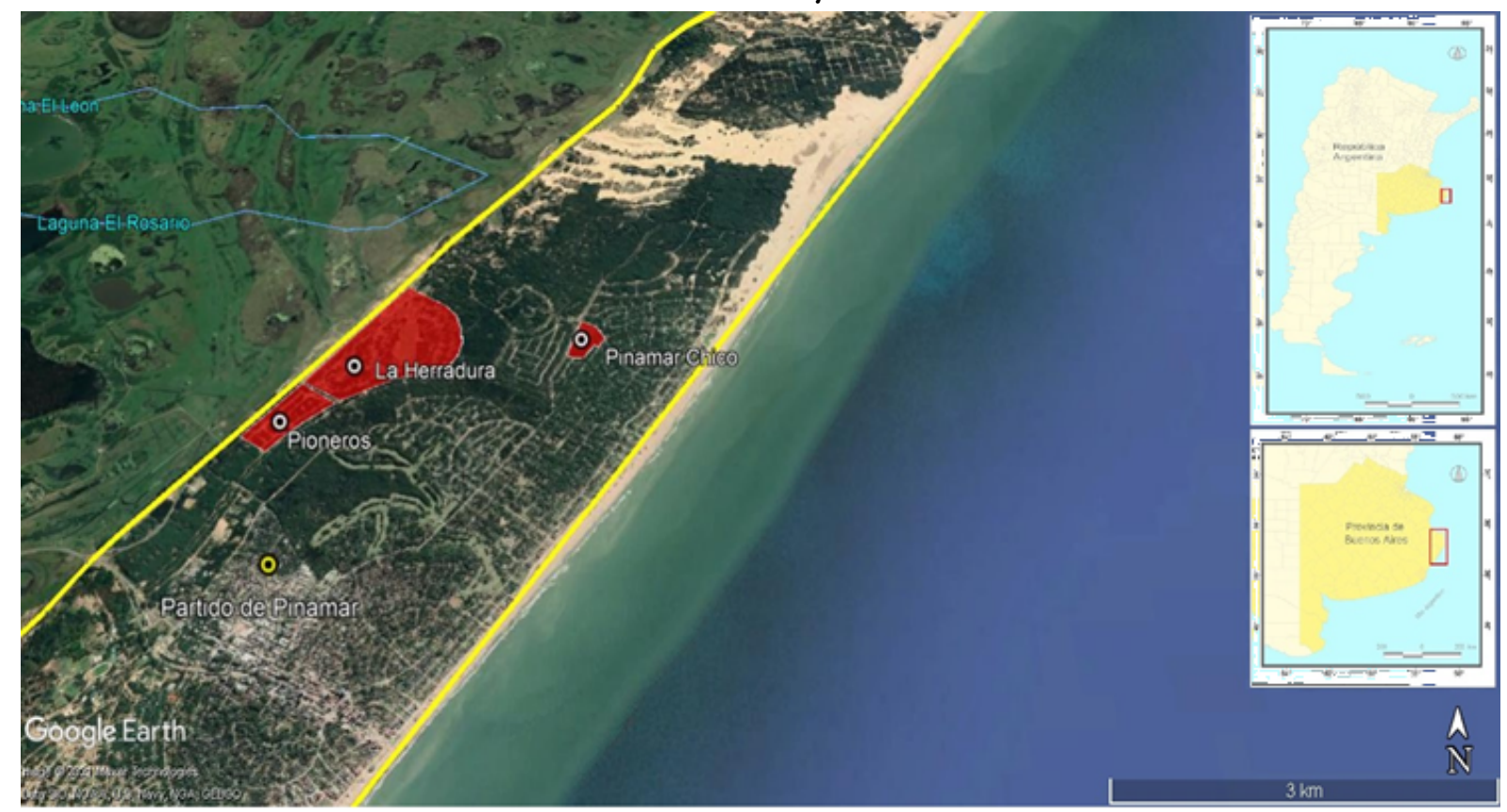

Los principales emprendimientos urbanos cerrados del Partido de Pinamar.

Fuente: elaboración propia a partir de Google Earth.

- Por último, en el Partido de Villa Gesell el avance de urbanizaciones cerradas también ha tomado un impulso importante en el periodo analizado. Sin embargo, la reacción social ante determinados proyectos urbanos ha sido diferente. Para justificar dicha afirmación, se seleccionaron dos casos que confrontaron a un sector de la comunidad organizada de Villa Gesell con el Estado municipal y empresarios que proyectaron un complejo turístico-habitacional y una urbanización privada en áreas costeras de la localidad. En el primer caso, en el año 2007, la empresa española constructora y de desarrollo inmobiliario Ingeniería, Construcción y Servicios (Ingeconser) hizo público el proyecto urbano Altamar, Ciudad Natural. El conflicto con desarrollos inmobiliarios se agudizó dos años después. Posteriormente, en 2009, la empresa NB Developer S. A. anunció la construcción del complejo turístico-habitacional denominado Mandalay. La oferta de servicios de calidad, la generación de empleo y el fortalecimiento local fueron algunos de los argumentos sostenidos por los posicionamientos a favor del desarrollo urbano (Hernández, 2020). Sin embargo, lo que se discute es que ambos proyectos profundizan el distanciamiento de Villa Gesell respecto al modelo de desarrollo fundacional. En ese sentido, el Municipio de la ciudad no evitó la alteración de dunas costeras para la realización de estos megaproyectos inmobiliarios. Los pobladores iniciaron reclamos al Concejo Deliberante 
para que detenga la destrucción del relieve; también exigieron al Ejecutivo comunal y otras autoridades municipales. Ante la falta de respuestas, decidieron obstaculizar la labor de las máquinas y realizar un acampe, con el objetivo de interrumpir el movimiento de terrenos (Marino, 2012). Esta reacción espontánea de un grupo de pobladores que se organizaron y agruparon permitió conformar lo que se conoció como la Asamblea en Defensa del Médano Costero. La presentación ante el Poder Judicial es la estrategia que más expectativa generó en el sector movilizado para dirimir a su favor el conflicto (Hernández, 2020). Después de transitar instancias legales, en 2012, la Fiscalía de Estado ordena a la Municipalidad restringir las construcciones y permitió a los vecinos participar del control de los planos y de los estudios de impacto ambiental (Marino, 2012).

Todo indica que los Partidos de La Costa, Pinamar y Villa Gesell se constituyeron en destinos turísticos en los que, paralelamente, la propiedad urbana cerrada se ha replicado y expandido con un ritmo sostenido. Más allá de los intersticios jurídicos existentes o la "pasividad" de ciertos sectores sociales ante la intensidad edilicia, siempre hay espacios para que la sociedad civil, de base territorial, se organice y presente resistencia ante cualquier desequilibrio ambiental que surja. La acumulación por desposesión, concepto desarrollado por David Harvey (2007), expone los efectos políticos y territoriales del urbanismo neoliberal. La desposesión de espacios costeros, causada por la expansión de los emprendimientos urbanos cerrados, permite el ingreso de actores privados hacia la especulación en el mercado de los suelos y a la mercantilización de la naturaleza.

El valor ecológico y paisajístico explica la presión antrópica por su ocupación y uso, expresados en el periodo histórico actual, mediante proyectos de inversión del sector inmobiliario -mercantilización de la naturaleza-. Se configura, entonces, una urbanización escasamente planificada y donde actores sociales históricamente vinculados con el territorio, como los residentes permanentes, no tienen incidencia en la toma de decisiones frente a sus comunidades y entorno natural. Este modelo de gestión política y económica ha tendido a permitirle al capital "una mayor libertad de acción como ordenador territorial, poniendo en crisis la relación entre el espacio público y el espacio privado, con una clara tendencia al incremento de este último" (Ciccolella, 2007, p. 126). Del mismo modo, Verón y Barragán Muñoz (2015) afirman que los grupos desarrolladores inmobiliarios han sido los que promovieron la transformación del ecosistema. Se han creado barrios privados de la magnitud de verdaderas ciudades, con una serie de servicios y amenities diferenciados por zonas que han modificado y privatizado el ecosistema. El principal impacto de estos emprendimientos se relaciona con la privatización y prohibición del acceso y disfrute público del ecosistema. En definitiva, un grupo de actores se han apropiado de distintos servicios culturales como el ocio y el disfrute estético y paisajístico del espacio abordado.

En este contexto, aporta que el incremento de la población, de la superficie urbana y de las actividades económicas ocasionó el aumento de los problemas ambientales. Según Isla (1995), la mala planificación del frente urbano y la pavimentación de las avenidas (en particular, las costaneras) redujeron los cordones medanosos o directamente los eliminaron, destruyendo al mismo tiempo las defensas naturales contra el oleaje y las tormentas. En consecuencia, por ejemplo, los efectos de las sudestadas fueron cada vez más graves, como las ocurridas durante 1993 en Santa Teresita, Mar del Tuyú y Pinamar, que derribaron numerosas casas y construcciones de las playas.

En este escenario, por mencionar otro ejemplo, la zona norte del Partido de Pinamar conserva una de las más importantes reservas de médanos costeros, que son garantía de la estabilidad de la playa y componente esencial de otros procesos naturales. Pero diversos usos e intervenciones vulneraron a lo largo de los años la estructura del sistema playa-médano. Dicha zona presenta una alta presión antrópica, dada su contigüidad con la trama urbana de Pinamar y por las obras civiles que se vienen desarrollando en su entorno (Isla, Cortizo y Turno Orellano, 2001). 


\section{Conclusiones}

El estudio evidencia el impacto de la acción antrópica en la configuración urbana y costera de los Partidos de La Costa, Pinamar y Villa Gesell. Se demuestra, en las distintas etapas analizadas, que el espacio litoral es la clave en la evolución y la configuración territorial. Concretamente, el uso de la playa y su entorno natural inmediato se transforma en el objeto más valorado en las distintas fases históricas.

La utilización de la técnica del análisis geohistórico en el área objeto de estudio fue útil para observar y describir la evolución temporal y espacial desarrollada sobre el área costera. La periodización elaborada permite reconocer las modificaciones vinculadas con la presión antrópica ejercida sobre el espacio litoral. En la primera etapa del siglo XX, los propietarios de los territorios correspondientes a los Partidos de General Lavalle y General Madariaga tenían como objetivo principal la plantación de distintas especies arbóreas y vegetales con la finalidad de fijar los médanos y estimular los asentamientos de población. Hacia la década del 30, lotearon sus estancias conformando los primeros pueblos costeros. A partir del segundo periodo, el turismo pasó a ser la práctica estructurante de todas las ciudades costeras, fragmentando el territorio de forma tal que, en 1978, fundamentó el desmembramiento territorial, dando lugar a cinco partidos. Así nacieron, entre otros, los municipios de La Costa, Pinamar y Villa Gesell, como una angosta pero extensa franja litoral. Para finalizar, en la última fase, se puede afirmar que la especulación inmobiliaria caracterizó el devenir de las ciudades costeras. Como consecuencia de ello, se intensificó el aprovechamiento de los servicios culturales del ecosistema costero en detrimento de los de regulación. Ello ha posibilitado que, en la actualidad, coexistan en el territorio formas tradicionales de ocupación junto con otras, distinguidas por la impronta que le otorgan las urbanizaciones cerradas al territorio.

Los resultados del trabajo reflejan que los Partidos de La Costa, Pinamar y Villa Gesell han modificado, de manera determinante, su impronta fundacional. Originalmente fueron concebidas como un entorno escénico para una vida social alejada de la vida cotidiana y de los contrastes sociales, adecuadas para realizar paseos, actividades recreativas y el disfrute de los paisajes. Sin embargo, las playas naturales fueron transformadas paulatinamente en balnearios urbanos para el turismo masivo. Si bien aún persiste en el discurso publicitario una promoción de los paisajes costeros, en la preservación y cuidado de ciertos espacios naturales, la realidad no refleja esta afirmación.

En síntesis, no es desacertado afirmar que los Partidos Urbanos de La Costa, Pinamar y Villa Gesell se hallan inmersos, en mayor o menor medida, en un proceso de litoralización. La conjunción de actividades económicas, el aumento de la población y la expansión de emprendimientos urbanos, ha ido evolucionando de manera sostenida en las últimas décadas del siglo XX y se ha profundizado en las primeras del siglo XXI. No es incoherente afirmar que, si las autoridades municipales no adoptan medidas destinadas a equilibrar este conjunto de elementos, la progresión de los mismos devendrá en un impacto negativo cada vez mayor sobre el espacio litoral.

Las respuestas necesarias para asegurar un desarrollo sostenible de las zonas costeras han sido, hasta el momento, insuficientes. Por ello, se torna necesario tomar medidas para disminuir o revertir la degradación de la zona costera del área objeto de estudio. El objetivo primordial para abordar el proceso de litoralización es la aplicación de los principios de la Gestión Integrada de las Áreas Litorales. La tendencia actual del mismo hace necesaria una mayor preocupación de los poderes públicos por administrar mejor este capital natural común.

\section{REFERENCIAS}

Barragán Muñoz, J. M. (2003). Medio ambiente y desarrollo en áreas litorales. Introducción a la planificación y gestión integradas. Cádiz: Servicio de Publicaciones de la Universidad de Cádiz. 
Barragán Muñoz, J. M. (2012). Manejo Costero Integrado en Iberoamérica: Diagnóstico y propuestas para una nueva politica pública. Madrid: CYTED.

Benseny, G. (2012). La conformación espacial y evolución turística de Villa Gesell (Argentina). Primer Taller de Turismo Internacional Historia y Turismo. Universidad Nacional de Mar del Plata, Facultad de Humanidades.

Benseny, G. (2008). Turismo en territorio litoral. Desigualdades urbanas originadas por la urbanización turística. En S. M. Arnaiz Burne y A. C. Dachary (Eds.), Turismo y desarrollo. Crecimiento y pobreza (pp. 311-334). Jalisco: Universidad de Guadalajara.

Bértola, G. (2006). Morfodinámica de playas del sudeste de la provincia de Buenos Aires (1983 a 2004), Latin American journal of sedimentology and basin analysis, 13(1), 31-57.

Bertoncello, R. (1992). Configuración socio-espacial de los balnearios del Partido de La Costa (Provincia de Buenos Aires). Territorio, 5, 18-55.

Bohmer, R. (2012). La historia del nacimiento de Pinamar. Recuperado de: http://www.dpinamar.com.ar/noticias-p inamar/historia-de-pinamar-creacion.html

Bouvet, Y., Desse, R., Morrell, P. y Villar, M. C. (2005). Mar del Plata (Argentina): La ciudad balnearia de los porteños en el Atlántico Suroccidental. Investigaciones Geográficas, 36, 61-80.

Ciccolella, P. (2007). Transformaciones recientes en las metrópolis latinoamericanas. En M. V. Fernández Caso y R. Gurevich (Comp.), Geografia: Nuevos temas, nuevas preguntas. Un temario para su enseñanza (pp. 125-145). Buenos Aires: Ed. Biblos.

Content LAB (20 de agosto de 2021) Playas vírgenes y mar, los inigualables "amenities" de Northbeach. Diario La Nación. Recuperado de https://www.lanacion.com.ar/propiedades/playas-virgenes-y-mar-los-inigualables-ame nities-de-northbeach-nid20082021/

Dadon, J. (1999). Gestión de sistemas con baja biodiversidad: Las playas arenosas del Noreste de la Provincia de Buenos Aires. En S. Matteucci, O. Solbrig, J. Morello y G. Halffter (Eds.), Biodiversidad y uso de la tierra. Conceptos y ejemplos de Latinoamérica (pp. 529-548). Buenos Aires: EUDEBA.

Dadon, J. (2003). Impactos ambientales del turismo costero en la provincia de Buenos Aires. Buenos Aires: FCEN, UBA.

Dadon, J. (2005). Historia ambiental y turismo en la costa bonaerense: de playas, vacaciones y ecología. Todo es Historia, 450, 54-62.

Dadon J. y Matteucci, S. (2006). Caracterización de las grandes regiones costeras argentinas. En F. Isla y C. Lasta (eds.), Manual de Manejo Costero para la Provincia de Buenos Aires. Mar del Plata: Universidad Nacional de Mar del Plata. IDRC-EUDEM. Recuperado de: https://www.researchgate.net/profile/Silvia_Matteucci/publication/2 71487769_Caracterizacion_de_las_grandes_regiones_costeras_de_la_Argentina/links/54c8df030cf289f0ced 10777/Caracterizacion-de-las-grandes-regiones-costeras-de-la-Argentina.pdf

D'amico, G. (2009). Fragilidad de los espacios litorales: Lineamientos para comprender la erosión costera inducida en el litoral marítimo bonaerense. El caso de la localidad de Mar del Tuyú. Geograficando, 5(5), 169-186. Recuperado de: http://www.fuentesmemoria.fahce.unlp.edu.ar/art_revistas/pr.4448/pr.4448.pdf

Elicabe, R. (2008). Partido de La Costa - Descubrimiento y fundación. Municipalidad de Santa Teresita. Recuperado de: https://www.santateresita.com.ar/partido.htm

Eidico (2021). Página web. https://eidico.com.ar/public/ [Consultado el 23/07/2021].

Frediani, J. (2008). Lógicas y tendencias de la expansión residencial en áreas periurbanas de ciudades medias (Tesis de doctorado). La Plata: Universidad Nacional de La Plata.

Frediani, J. (2009). Las nuevas periferias en el proceso de expansión urbana. El caso del Partido de La Plata. Geograficando, 5(5), 1-23. Recuperado de: https://www.geograficando.fahce.unlp.edu.ar/article/view/GEOv0 5 n05a05/pdf_52

Frediani, J., y Matti, C. (2007). Transformaciones urbanas en el partido de La Plata desde los años '90. ¿Hacia un modelo de ciudad compacta o difusa?. Geograficando, 2(2), 179-199. Recuperado de: https://www.geografican do.fahce.unlp.edu.ar/article/view/GEOv02n02a10

Gesell, R. (1983). Carlos I. Gesell, Su vida. Copyright by Rosemarie Gesell de Martínez Salas. Argentina. 
Harvey, D. (2007). Urbanismo y desigualdad social. Barcelona: Editorial Siglo Veintiuno.

Hernández, F. (2020). Estudio geográfico de un litigio judicial. Un caso en Villa Gesell (Provincia de Buenos Aires). Geograficando, 16(1), e067. En Memoria Académica. Recuperado de: http://www.memoria.fahce.unlp.edu.ar/ art_revistas/pr.11865/pr.11865.pdf

Horvat, A. (13 de enero de 2021) Costa Esmeralda: cómo se vive en el barrio privado más grande construido junto al mar. Diario La Nación. Recuperado de https://www.lanacion.com.ar/sociedad/costa-esmeralda-como-se-viv e-barrio-privado-nid2568093/

Instituto Nacional de Estadísticas y Censos (2010). Censo Nacional de Población y Vivienda 2010. Resultados Generales. Provincia de Buenos Aires. Localidades y Partidos de Argentina. Buenos Aires.

Instituto Nacional de Estadísticas y Censos (2016). Proyecciones de población por Municipio en la provincia de Buenos Aires 2010-2025. Ministerio de Economía. Subsecretaría de Coordinación Económica. Dirección Provincial de Estadística Recuperado de: http://www.estadistica.ec.gba.gov.ar/dpe/images/Proyecciones_x_m unicipio_2010-2025.pdf [Consulta 09/10/2020]

Isla, F. (1995). Efectos de las tormentas sudestadas en el litoral bonaerense durante 1993, Argentina. Resúmenes del VI Congreso Latinoamericano de Ciencias del Mar, Mar del Plata, Argentina, Pp. 111.

Isla, F., Cortizo, L. y Turno Orellano, H. (2001). Dinámica y evolución de las barreras medanosas, Provincia de Buenos Aires, Argentina. Revista Brasileira de Geomorfología, 1(2), 73-83.

Isla, F. (2010). Introducción al manejo de barreras medanosas. En F. Isla, y C. Lasta (Comp.), Manual de Manejo de Barreras Medanosas de la Provincia de Buenos Aires (pp. 7-25). Mar del Plata: EUDEM.

Mantecón, L. (2013). Consideraciones sobre el desarrollo urbanístico y la problemática ambiental en la costa de la provincia de Buenos Aires. Revista Electrónica del Instituto de Investigaciones "Ambrosio L. Gioja", 7(10), 118-143.

Mantobani, J. (2002). Entre el trigo y la espuma. Mar del Plata y el problema de la creación de los balnearios del Sudeste de la provincia de Buenos Aires a fines del siglo XX. Mar del Plata: Universidad Nacional de Mar del Plata, 230 pp.

Manzano, F. y Velázquez, G. (2018). De un área desértica e improductiva a un espacio ideal para la especulación: las percepciones sobre la costa atlántica bonaerense. Boletim Goiano De Geografia, 2(38), 224-250.

Marino, C. (21 de marzo de 2012). Villa Gesell: La justicia ordenó frenar dos emprendimientos hoteleros costeros. Diario Letra P. Recuperado de https://www.letrap.com.ar/nota/2012-3-21-villa-gesell-la-justicia-ordeno-frena r-dos-emprendimientos-hoteleros-costeros

Masor, O. (1995). La historia de Villa Gesell. Bariloche Impresiones. Argentina.

Maya, M. (2019). Urbanizaciones cerradas en Mar del Plata: ordenamiento territorial y construcción social del espacio. Boletin Geográfico, 1(41), 79-94. Recuperado de: http://revele.uncoma.edu.ar/htdoc/revele/index.php/geograf ia/article/view/2367/59017

Maya, M. (2018). Urbanizaciones cerradas, fragmentación socioterritorial en el periurbano sur de Mar del Plata. Estudios Sociales Contemporáneos, 19, 18-45. Recuperado de: http://bdigital.uncu.edu.ar/11556

Maya, M. (2017). El crecimiento de urbanizaciones cerradas y la fragmentación socioterritorial en la ciudad de Mar del Plata. Pasado abierto, 3(6). Recuperado de: http://fh.mdp.edu.ar/revistas/index.php/pasadoabierto/article $/$ view/2493/2573

Morello, J. (1983). Ecología, preferencias turísticas y ambientes extraurbanos. En Medio ambiente y turismo (pp. 55-72). Buenos Aires: CLACSO.

Municipalidad de La Costa. https://www.lacosta.gob.ar/turismo/ [Consulta 20 de julio de 2020].

Municipalidad de Pinamar. https://www.pinamar.gov.ar/historia [Consulta 28 de junio de 2020].

Municipalidad de Villa Gesell. http://www.gesell.gob.ar/ [Consulta 20 de octubre de 2020].

Ordoqui, J. y Hernández, F. (2009). Caracterización socioterritorial de los asentamientos turísticos-balnearios del litoral marítimo de la Provincia de Buenos Aires. Revista Universitaria de Geografia, 18(1), 105-140.

Pinamar S. A. https://www.pinamar.com.ar/ [Consulta 28 de julio de 2021].

Programa de las Naciones Unidas para el medio ambiente (PNUMA) (2004). GEO América Latina y el Caribe. Perspectivas del medio. Universidad de Costa Rica. Observatorio del Desarrollo. 
Santos, M. (1996a). Por uma Geografía Nova. Sâo Paulo: Editorial Hucitec.

Santos, M. (1996b). Metamorfosis del espacio habitado. Barcelona: Editorial OikosTau.

Tomadoni, C. (2007). A propósito de las nociones de espacio y territorio. Gestión y Ambiente, 10(1), 53-65. Colombia: Universidad Nacional de Colombia. Medellín. Recuperado de: http://www.redalyc.org/articulo.oa?id=16941 9796004

Tovar, R. (1984). Enfoque geohistórico. Caracas: Biblioteca de la Academia Nacional de la Historia.

UN-Habitat (2010). De la urbanización acelerada a la consolidación de los asentamientos humanos en América Latina y el Caribe: El espacio regional. Santiago de Chile: UN-HABITAT.

Verón, E. (2012). Privatización De Los Ecosistemas Litorales Urbanizaciones Privadas En El Partido De La Costa, Buenos Aires. En M. M. Eraso (Dir.), Gestores Costeros II. Experiencias en Areas Litorales de la provincia de Buenos Aires. Mar del Plata: Ed. EUDEM. Universidad Nacional de Mar del Plata.

Verón, E. (2006). El Partido de la Costa: Un análisis histórico de sus principales problemáticas socioeconómicas y ambientales. En Asociación Argentina de Historia Económica, Actas XX Jornadas de Historia Económica (pp. 1-19). Mar del Plata.

Verón, E. (2014). Lógicas territoriales, representaciones y gestión de un espacio fragmentado en torno a problemáticas socioambientales. Estudio comparado de los distritos de La Costa, Pinamar, Villa Gesell, General Lavalle y General Madariaga (Tesis de doctorado en Geografía). Universidad Nacional del Sur, Universidad de Cádiz.

Verón, E. y Barragán Muñoz, J. (2015). Transformación y funcionalización del Socioecosistema Litoral Norte de la provincia de Buenos Aires, Argentina; Universidad Nacional del Sur. Departamento de Geografía y Turismo. Revista Universitaria de Geografía, 24, 91-117.

Vidal-Koppmann, S. (2014). Countries y barrios cerrados. Mutaciones socio-territoriales de la región metropolitana de Buenos Aires. Buenos Aires: Editorial Dunken.

Vidal-Koppmann, S. (2015). Urbanizaciones privadas en zonas costeras: Del goce pleno de la naturaleza a los negocios inmobiliarios. La costa atlántica argentina y las estrategias de ordenamiento territorial. Revista Argentina como geografia, N. ${ }^{\circ} 1,101-115$.

Villar, M. C. (2003). Espacio, mito y representaciones sociales. Algunos ingredientes y un desarrollo por el litoral marítimo argentino. Reflexiones Geográficas, Río Cuarto. 20 pp.

Villa Robles Ciudad- Pueblo. Web Oficial. https://www.villarobles.com/ [Consulta 25 de julio de 2021]

Zdruli, P. (2008). Litoralización. Recuperado de: https://studylib.es/doc/4711453/litoralizaci\%C3\%B3n 